\title{
Urban Dog Parks as Sources of Canine Parasites: Contamination Rates and Pet Owner Behaviours in Lisbon, Portugal
}

\author{
Ana Ferreira, ${ }^{1}$ Ana Margarida Alho, ${ }^{1}$ David Otero, ${ }^{1}$ Lídia Gomes, ${ }^{1}$ Rolf Nijsse, ${ }^{2}$ \\ Paul A. M. Overgaauw, ${ }^{3}$ and Luís Madeira de Carvalho ${ }^{1}$ \\ ${ }^{1}$ CIISA, Faculty of Veterinary Medicine, Universidade de Lisboa, Avenida da Universidade Técnica, 1300-477 Lisboa, Portugal \\ ${ }^{2}$ Department of Infectious Diseases and Immunology, Faculty of Veterinary Medicine, Utrecht University, Postbus 80165, \\ 3508 TD Utrecht, Netherlands \\ ${ }^{3}$ Institute for Risk Assessment Sciences, Division of Veterinary Public Health, Utrecht University, Postbus 80163, \\ 3508 TD Utrecht, Netherlands \\ Correspondence should be addressed to Ana Margarida Alho; margaridaalho@fmv.ulisboa.pt
}

Received 30 December 2016; Revised 2 March 2017; Accepted 25 July 2017; Published 30 August 2017

Academic Editor: Brian Buckley

Copyright (C) 2017 Ana Ferreira et al. This is an open access article distributed under the Creative Commons Attribution License, which permits unrestricted use, distribution, and reproduction in any medium, provided the original work is properly cited.

\begin{abstract}
Dog parks represent a recent trend in western countries, enabling owners to spend quality time with their pets in a controlled environment. Despite their growing popularity, few studies have been performed to date on these parks to investigate dog intestinal parasitic infections and soil contamination. The present study examined 369 faecal and 18 soil samples collected from 3 dog parks in Greater Lisbon, Portugal. Additionally, 102 interviews were performed with dog owners to assess dog-walking behaviours and parasite risk. In total, $33 \%$ of the faecal dog samples were infected with at least one parasitic agent: hookworms (16.5\%), Cryptosporidium spp. (11.9\%), Giardia spp. (11.4\%), Toxascaris leonina (1.1\%), Cystoisospora spp. (1.1\%), Toxocara spp. (0.5\%), and Sarcocystis sp. (0.3\%). The soil of all the parks was contaminated with hookworm eggs. This is the first study performed in a European urban area to assess canine faecal contamination and parasitic agents in dog parks. Our results highlight the potential of these parks as a source of transmission for canine parasites, including some with zoonotic potential. Public awareness and effective preventive measures should be promoted to minimise the health-risk impact to both animals and humans, under the scope of environmental and public health.
\end{abstract}

\section{Introduction}

In modern-day society, the human-animal bond has become stronger with pets playing an important role as a source of companionship, emotional support, and recreation. Dogs encourage easier social interactions between people and promote the physical and psychological health of their owners $[1,2]$. Despite the positive effects that pets can have on people's lives, this close bond may also compromise human health due to allergic reactions, trauma, and infectious diseases [2]. Dogs have been implicated in the transmission of more than 60 zoonotic infectious diseases [1], some of which are due to canine intestinal parasitic infections and are of serious concern. For instance, Toxocara spp. are responsible for visceral larva migrans (VLM), ocular larva migrans (OLM), covert toxocariasis, and neurological and atopic signs [3]. Some hookworms can cause cutaneous larva migrans (CLM) and eosinophilic enteritis [4]. Assemblages A and B in the protozoan genus Giardia are considered to have a zoonotic potential [5], and the risk of human infection by Cryptosporidium sp. from dogs, though limited, has not been excluded [6]. Until now, children, pregnant women, elderly, and immunocompromised people are all at a higher risk of disease resulting from parasitic zoonoses [7].

Dog parks (i.e., enclosed areas for domesticated dogs to play off-leash and socialise with other canines in a controlled environment) enable owners to spend quality time with their dogs. These areas promote social interactions among dogs and offer a safe setting for regular exercise in a controlled environment under the supervision of their owners [8]. Over the last decades, dog parks became very popular in urban areas and are one of the fastest growing segments of city parks. 
However, these parks may pose an increased risk for the transmission of parasitic zoonotic agents, via faecal and soil contact, among dogs, humans, and wildlife [8, 9]. Despite this, few studies investigating soil contamination and intestinal parasitic infections in dog parks have been carried out thus far, including one in Colorado, USA [10], and a second in Calgary, Alberta, Canada [8]. No studies have been performed in urban dog parks in Europe to date.

In order to assess faecal environmental contamination and intestinal parasites in frequenting purpose-built dog parks, faecal and soil samples were collected from such parks located in urban areas of Lisbon, Portugal. Interviews were conducted to assess owners' behaviour, veterinary care, and the owner-pet relationship.

\section{Materials and Methods}

2.1. Sampling Area. Three purpose-built dog parks located in Greater Lisbon were chosen, in order to represent this type of facility located in densely populated areas distributed throughout the city: (A) Algés, a $350 \mathrm{~km}^{2}$ parish with 48.665 inhabitants and 1.693 licensed dogs; (B) Benfica, a $465 \mathrm{~km}^{2}$ parish with 36.821 inhabitants and approximately 400 licensed dogs; and (C) Campo Grande, a $1.120 \mathrm{~km}^{2}$ parish with 31.813 inhabitants and about 1.700 licensed dogs (Figure 1). The dog parks were fenced with a double-gated entry and had shades, drainage, water sources, and covered garbage cans. All parks were regularly maintained, including ground cleaning. This study was conducted from October to December 2015. For a better representation of the visiting population, fresh faecal samples randomly distributed throughout the parks were collected every 15 days, at different periods of the day (morning, midday, and afternoon). Once a month over the same period, soil samples were collected from five distinct spots with a gardening spade and subsequently pooled (approximately 250 grams). Samples were obtained from a depth of between 0 and $5 \mathrm{~cm}$ of grass ( 3 samples/park) and gravel (3 samples/park). Although cleaning and disinfection activities are implemented on a regular basis, the authors were unaware of any of them performed on the surveyed parks immediately prior to sampling dates.

Over the same period, 102 owners walking their dogs in the three dog parks were interviewed.

\subsection{Coprological Analysis}

2.2.1. Parasite Egg Isolation and Identification. A Centrifugal Sedimentation Flotation (CSF) technique was used [11]. Briefly, 3-5 g of each faecal sample was homogenised in $55 \mathrm{ml}$ of distilled water and sieved through a tea strainer into a tube. Tubes were centrifuged ( 3 minutes at $3000 \mathrm{rpm}$ ) and the supernatant was discarded. A third of the tube was filled with sucrose solution (specific density: $1.3 \mathrm{~g} \mathrm{ml}^{-1}$ ), vortexed, filled again with sucrose solution, and centrifuged ( 3 minutes at $3000 \mathrm{rpm})$. Tubes were then filled with sucrose solution until a convex meniscus was formed and a coverslip was then placed immediately on the top. After 25 minutes, the coverslip was placed on a slide for observation using an optical microscope at $100 \mathrm{x}-400 \mathrm{x}$ magnification. Eggs, oocysts, and cysts were identified morphologically according to published guides [12-14]. Names of the parasites of genus Cystoisospora followed a recent taxonomic revision [15].

2.2.2. Faecal Smears. A faecal smear, stained by the modified Ziehl-Neelsen technique [16], was performed on each sample. Briefly, a small amount of faeces was spread over a slide to form a thin layer, using a stirring rod. After drying, smears were fixated with methanol for 1 minute, covered with fuchsine for 10 minutes, and washed under running water. They were subsequently washed with $1 \%$ hydrochloric alcohol to remove excess fuchsine and washed again with running water. Slides were then covered with $0.4 \%$ malachite green for 30 seconds, washed again with running water, and finally left to air-dry. Smears were observed at 1000x magnification for the detection of Giardia sp. cysts, as transparent oval bodies with 4 nuclei, and Cryptosporidium sp. oocysts, as round oocysts frequently containing typical crescent shaped sporozoites stained with a pink-reddish colour. A minimum of 50 fields were observed per slide. Genotyping of Giardia spp. and Cryptosporidium spp. isolates was not possible to perform.

2.3. Soil Analysis. Soil samples were analysed using a modified Sieving and Centrifugal Sedimentation Flotation (CSF) technique $[17,18]$. For each sample, one hundred grams of soil was weighed, mixed with $100 \mathrm{~mL}$ of $5 \%$ Tween-20 solution, and then homogenised for 10 minutes and allowed to stand overnight. The contents were then sieved (diameters $1.000 \mathrm{~mm}, 0.500 \mathrm{~mm}, 0.250 \mathrm{~mm}, 0.150 \mathrm{~mm}, 0.063 \mathrm{~mm}$, and $0.020 \mathrm{~mm}$ ) and washed under running water for 30 minutes. The sediment present in the $0.063 \mathrm{~mm}$ and $0.020 \mathrm{~mm}$ sieves was resuspended in distilled water and allowed to stand overnight. The sediment was then resuspended with distilled water and the tubes were centrifuged for 3 minutes at $2000 \times \mathrm{g}$. The supernatant was discarded and the parasite eggs were collected from sediment and identified as mentioned above.

2.4. Interviews. Multiple-choice questionnaires were completed as oral face-to-face interviews conducted with 102 dog owners walking their dogs in each one of the three dog parks. Overall, 34 questionnaires were performed per park. Owners were asked several questions intended to assess dog-walking behaviours, including park visitation frequency, animal healthcare, and dog-owner habits.

2.5. Statistical Analysis. Statistical analysis was performed using R, version 3.1.3, and the extension R Commander (the R Foundation for Statistical Computing, 2013). Chi-square or Fisher's exact tests were used to compare proportions and a probability $p$ value $<0.05$ was considered as statistically significant. Exact binomial 95\% confidence intervals (CI) were established for proportions.

\section{Results}

3.1. Faecal Samples. In total, 369 faecal samples were collected: 125 from Algés (A), 124 from Benfica (B), and 120 from Campo Grande (C). A total of 18 soil samples were also collected, 6 from each park (3 from grass and 3 from gravel surfaces). The overall prevalence of various parasites in the 


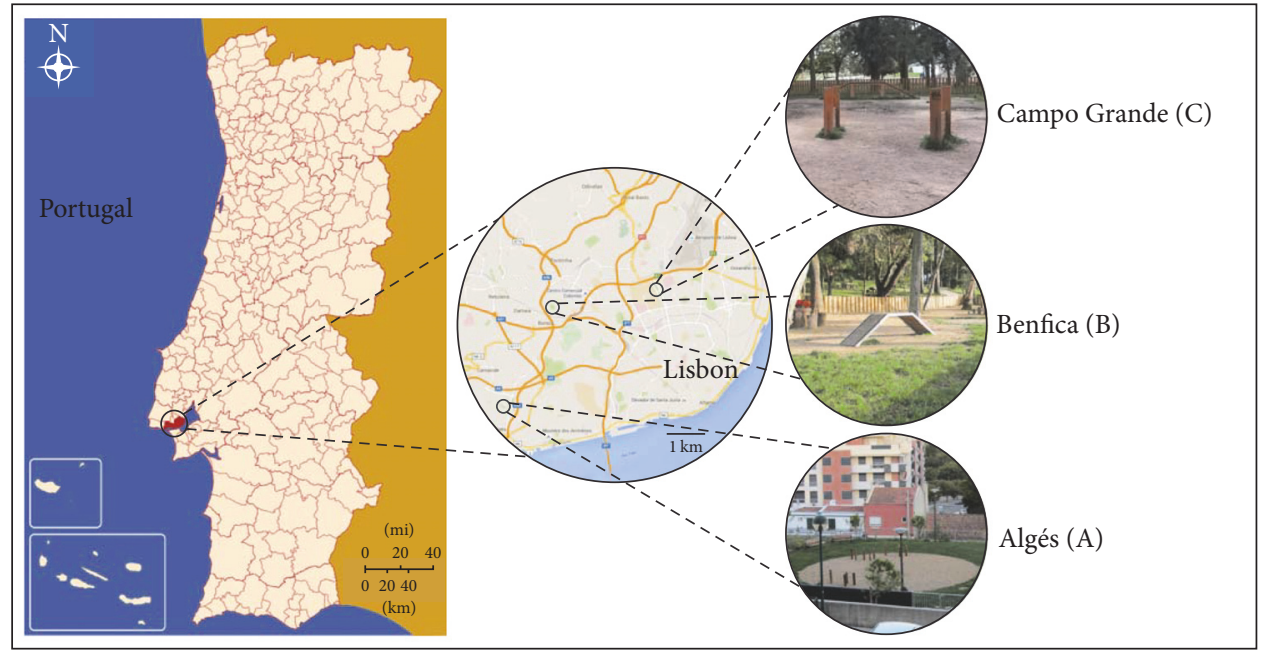

FIGURE 1: Map highlighting the three dog parks assessed in Greater Lisbon, Portugal.

TABLE 1: Prevalence of the parasites detected in faecal samples collected in three dog parks (A, B, and C) of Greater Lisbon, Portugal.

\begin{tabular}{|c|c|c|c|c|}
\hline & $\begin{array}{c}\mathrm{A}(n=125) \\
(95 \% \mathrm{CI})\end{array}$ & $\begin{array}{c}\mathrm{B}(n=124) \\
(95 \% \mathrm{CI})\end{array}$ & $\begin{array}{c}\mathrm{C}(n=120) \\
(95 \% \mathrm{CI})\end{array}$ & $\begin{array}{c}\text { Total }(n=369) \\
(95 \% \mathrm{CI})\end{array}$ \\
\hline Hookworms & $\begin{array}{c}14.4 \% \\
(9.0-22.1)\end{array}$ & $\begin{array}{c}18.5 \% \\
(12.4-26.7)\end{array}$ & $\begin{array}{c}16.7 \% \\
(10.7-24.8)\end{array}$ & $\begin{array}{c}16.5 \% \\
(13.0-20.8)\end{array}$ \\
\hline Cryptosporidium spp. & $\begin{array}{c}12.0 \% \\
(7.1-19.3)\end{array}$ & $\begin{array}{c}15.3 \% \\
(9.7-23.2)\end{array}$ & $\begin{array}{c}8.3 \% \\
(4.3-15.2)\end{array}$ & $\begin{array}{c}11.9 \% \\
(8.9-15.8)\end{array}$ \\
\hline Giardia spp. & $\begin{array}{c}16.0 \% \\
(10.3-23.9)\end{array}$ & $\begin{array}{c}6.5 \% \\
(3.0-12.7)\end{array}$ & $\begin{array}{c}11.7 \% \\
(6.8-19.1)\end{array}$ & $\begin{array}{c}11.4 \% \\
(8.4-15.2)\end{array}$ \\
\hline Cystoisospora spp. & $\begin{array}{c}0.8 \% \\
(0.0-5.0)\end{array}$ & $\begin{array}{c}1.6 \% \\
(0.3-6.3)\end{array}$ & $\begin{array}{c}0.8 \% \\
(0.0-5.2)\end{array}$ & $\begin{array}{c}1.1 \% \\
(0.4-2.9)\end{array}$ \\
\hline Toxascaris leonina & 0 & 0 & $\begin{array}{c}3.3 \% \\
(1.1-8.8)\end{array}$ & $\begin{array}{c}1.1 \% \\
(0.4-2.9)\end{array}$ \\
\hline Toxocara spp. & $\begin{array}{c}0.8 \% \\
(0.0-5.0)\end{array}$ & $\begin{array}{c}0.8 \% \\
(0.0-5.1)\end{array}$ & 0 & $\begin{array}{c}0.5 \% \\
(0.1-2.2)\end{array}$ \\
\hline Sarcocystis sp. & $\begin{array}{c}0.8 \% \\
(0.0-5.0)\end{array}$ & 0 & 0 & $\begin{array}{c}0.3 \% \\
(0.0-1.7)\end{array}$ \\
\hline Total of positive samples & $\begin{array}{c}35.2 \% \\
(27.0-44.3)\end{array}$ & $\begin{array}{c}31.5 \% \\
(23.6-40.5)\end{array}$ & $\begin{array}{c}32.5 \% \\
(24.4-41.7)\end{array}$ & $\begin{array}{c}33.1 \% \\
(28.3-38.2)\end{array}$ \\
\hline
\end{tabular}

faecal samples from the three different parks is presented in Table 1.

Hookworms were the most prevalent group of parasites detected. Cryptosporidium spp., Giardia spp., and Cystoisospora spp. were also identified in all three parks whereas Toxocara spp. were detected in only two parks and Toxascaris leonina and Sarcocystis sp. were detected in only one. Dog park A showed a greater biodiversity in its parasitic fauna with 6 of the 7 parasite groups diagnosed, whereas dog parks $\mathrm{B}$ and $\mathrm{C}$ had only 5 different types of parasites (Figure 2). No significant statistical differences were detected between parks $(p=0.81)$.

3.2. Soil Samples. In total, 18 soil samples were collected, 6 per each park ( 3 from grass and 3 from gravel). Five of the 9 samples (55.6\%) from grassed areas contained hookworm eggs (Ancylostomatidae) whereas 0/9 samples from gravel areas had hookworm eggs, showing a significant statistical difference between grassed and gravel areas $(p=0.03)$. Overall, 27.8\% (5/18) of the soil samples (all from grassed areas) were contaminated with hookworm eggs, in the three assessed parks: $33.3 \%$ (CI 6.0-75.9\%) from A, 16.7\% (CI 0.9-63.5\%) from B, and 33.3\% (CI 6.0-75.9\%) from C. Eggs were only found in grassed areas. Regarding soil samples, no significant statistical differences were detected between the parks $(p=1)$.

3.3. Interviews. It was found that $40.2 \%$ of the dogs present in the parks live in a home/dwelling with at least one other animal (most with other dogs and cats and a minority with birds, rabbits, or guinea pigs). Regarding daily walking, $82.3 \%$ were walked both on the streets and in parks, $16.7 \%$ only in 


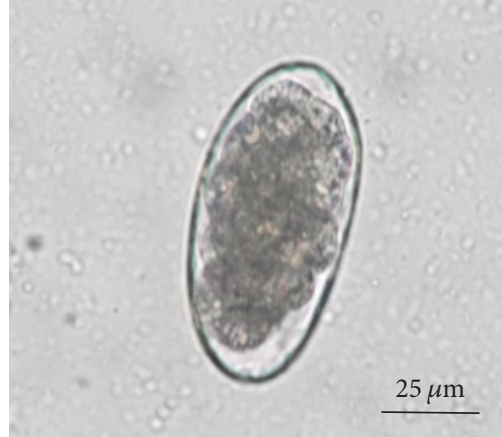

(a)

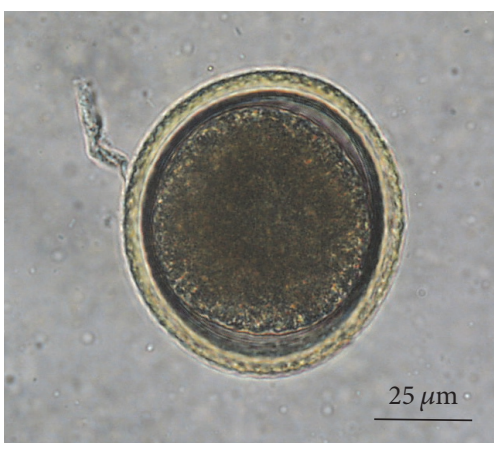

(d)

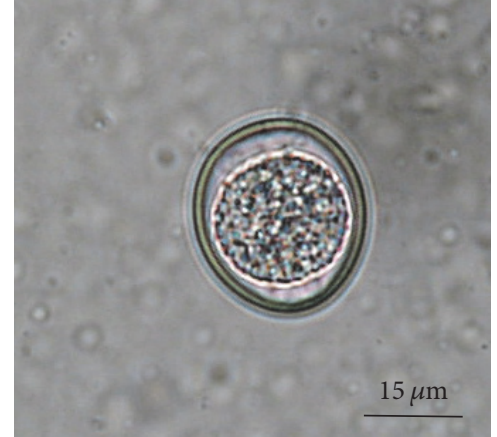

(b)

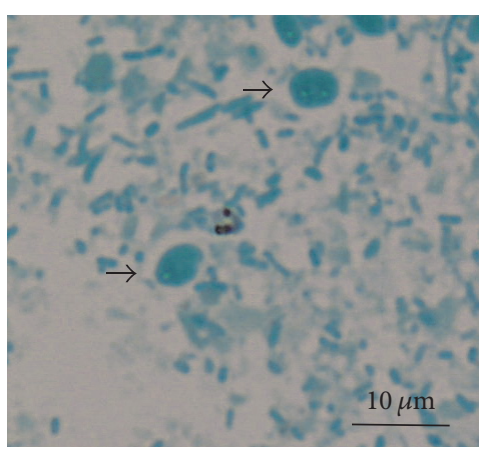

(e)

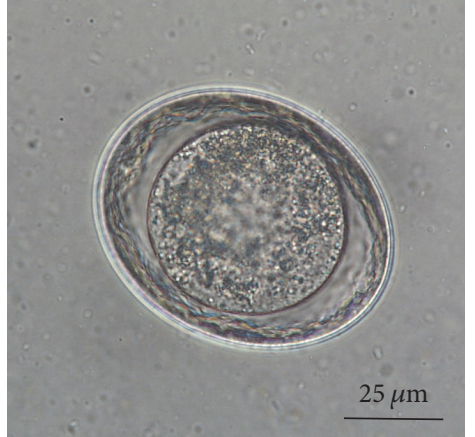

(c)

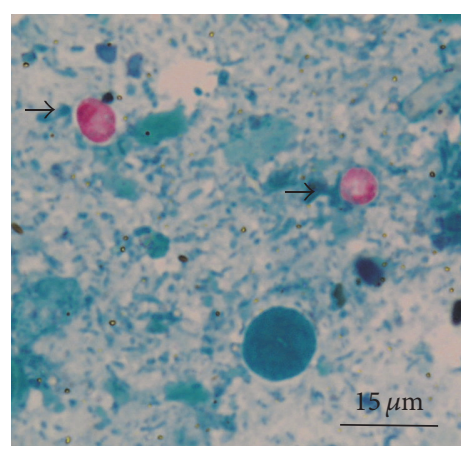

(f)

Figure 2: Some of the eggs, cysts, and oocysts detected in fresh faecal samples collected from dog parks using Centrifugal Sedimentation Flotation technique and faecal smears stained by the modified Ziehl-Neelsen technique. (a) Morulated hookworm egg; (b) Cystoisospora spp. unsporulated oocyst; (c) nonembryonated Toxascaris leonina egg; (d) nonembryonated Toxocara canis egg; (e) Giardia spp. cysts in faecal smear (arrows); (f) Cryptosporidium spp. oocysts in faecal smear (arrows).

parks, and $1.0 \%$ in parks and open field. In addition, $41.2 \%$ of the respondents mentioned visiting with their dogs more than one of the dog parks located in Lisbon.

Of the total respondents, $50.0 \%$ visited the park daily, $29.4 \%$ at least once a week, and $20.6 \%$ less than $1-3$ times a month. Most dog owners walked their dogs off-leash (57.8\%), $17.6 \%$ on-leash, and $24.5 \%$ both $(82.3 \%$ with off-leash activity, overall). Almost all owners, $94.1 \%$, claimed to collect their dog's faeces.

Regarding animal healthcare, $93.1 \%$ of dog owners answered to have taken their dog to a veterinarian consultation in the previous 12 months. Concerning anthelmintic treatments, $89.9 \%$ of the owners stated to have internally dewormed their dogs in the previous six months. However, when asked regarding its specific frequency, $14.5 \%$ answered three times a year, $41.0 \%$ twice a year, $13.3 \%$ once a year, and only $27.7 \%$ at least four times a year.

The most commonly used anthelmintic drug $(72.7 \%$ of respondents) was the combination of praziquantel-pyrantel embonate with a third molecule (febantel, oxantel, or fenbendazole).

In $82.4 \%$ of the households, the dog was allowed to visit the owners' bedroom, $75.5 \%$ were allowed to lick their owners' faces, and $43.1 \%$ were allowed to sleep with the owners in their beds.

\section{Discussion}

This is the first study performed to assess canine faecal contamination and parasitic agents in urban dog parks and dogs frequenting such parks in Europe. The three parks had similar rates of contamination, with one-third of dog faecal samples positive for at least one parasite. Hookworms were the parasite group detected with the highest prevalence (16.5\%) in all sampled parks. In Europe, there are two main species of hookworms: Ancylostoma caninum (the potentially zoonotic helminth responsible for cutaneous larva migrans) and Uncinaria stenocephala (nonzoonotic). As faecal culture and larvae examination were not performed, these two species were not differentiated and zoonotic potential could not be assessed. Although faecal samples were fresh, they were directly exposed to sunlight and warm temperatures for some hours until collection. Indeed, according to Anderson (2000) [19], the embryo formation of A. caninum eggs easily takes place and greatly varies with environmental temperature, ranging from $6-12$ days at $12^{\circ} \mathrm{C}$ to $10-12$ hours at $30^{\circ} \mathrm{C}$. Similarly, U. stenocephala eggs can hatch within 12 hours at $20^{\circ} \mathrm{C}$. Considering the high temperatures registered in Lisbon during the study sampling period, this fact explains why the authors found several embryonated eggs, despite working with fresh collected samples. 
Concerning the percentage of hookworm eggs contaminating the herbage $(55.6 \%)$, it mirrors the results found also by other authors concerning both domestic and wild canids. Hookworm infections had been commonly reported in household, hunting, kennel, and farm canids from north and south of Portugal, being the predominant helminth eggs detected [20,21]. Although free-living nematodes may also be found when sampling herbage, they were distinguished by the characteristics of the adult stages (e.g., rhabditids) and by their eggs which are smaller and more transparent. Additionally, hookworm samples were found in parks where neither rabbits nor rodents were found, given the regular cleaning measures and rodent control program performed by municipal city services in these areas. In the present study, hookworm eggs were the only parasites found in soil samples, which suggests recent contamination, as these eggs do not generally persist for long periods in the environment [22]. Additionally, only grass samples were positive for parasite ova. The lack of ova in gravel samples is possibly explained by the large size of the gravel grains that do not retain parasitic elements, or by the fact that dogs prefer to defaecate on grass rather than on gravel. Furthermore, grass areas protect more the eggs from direct sun exposure in comparison with sandy areas, where eggs may have been destroyed by desiccation after direct sunlight exposure.

Protozoa were also found in all sampled parks, being more prevalent than nematodes. Indeed, a declining trend in the prevalence of intestinal helminths has been observed in certain countries over the last few decades, possibly explained by owner's increased awareness and consequent application of routine preventive anthelmintic treatments [7]. Such anthelmintics usually do not have label claims that include intestinal protozoa [7].

In the present study, oocysts of Cryptosporidium spp. were found in $11.9 \%$ of the faecal samples. This prevalence is in between the $4.8 \%$ of park-attending dogs from Colorado, United States of America [10], and the $14.7 \%$ detected in parkattending dogs from Calgary, Canada [8]. Lower prevalence was detected in other European countries, such as $0 \%$ in Belgium [23] and 2.6\% in France [24]. Cryptosporidium infection in dogs is mainly caused by Cryptosporidium canis whereas in humans it is mainly due to Cryptosporidium hominis. In fact, the risk of humans acquiring the infection from dogs seems to be minimal, mostly limited to immunocompromised individuals, although zoonotic potential has not been conclusively ruled out by the scientific community [6].

Giardia spp. were found in $11.4 \%$ of the faecal samples, again an intermediate value between the $7.6 \%$ in parkattending dogs from Colorado [10] and the $24.7 \%$ from Calgary [8], performed with direct immunofluorescence assay, a more sensitive method of detection. Giardia spp. trophozoites and cysts were searched using CSF and Ziehl-Neelsen staining of faecal smears. Although the latter technique is not much referred for detection of Giardia spp., it was chosen in this study because of its common use for the diagnosis of Cryptosporidium spp., allowing the simultaneous detection of both agents. This is an easy and well-suited detection method for general practice [25]. Similar studies conducted in other areas of Portugal using zinc sulphate showed prevalence of $7.4 \%$ in asymptomatic dogs and $15.5 \%$ in symptomatic dogs from Oporto [26], and 1.3\% in household dogs and $61.2 \%$ in kennel dogs from Évora [21].

In fact, Cryptosporidium spp. and Giardia spp. are frequently associated with waterborne outbreaks. In a study conducted in Lisbon to assess the presence of Cryptosporidium and Giardia in raw and treated water by immunofluorescence (IFA) microscopy and PCR, Cryptosporidium spp. oocysts were found in $53.6 \%$ of untreated and in $41.5 \%$ of treated water samples, whereas Giardia spp. cysts were detected in $58.0 \%$ of untreated and in $25.6 \%$ of treated water samples [27].

Although there is only one species of Toxocara in the dog (Toxocara canis), as dogs may also shed eggs of Toxocara cati due to coprophagy and as morphological distinction between T. canis and T. cati eggs is very difficult with light microscopy, the authors only indicated the genus. The prevalence of dogs shedding Toxocara eggs in the present study was low, particularly when compared to the results found by Otero et al. [28] who detected $63.2 \%$ of soil and $15.8 \%$ of faecal samples positive for Toxocara spp. in urban public parks and children playground sandpits of Lisbon. A higher prevalence of dogs shedding Toxocara eggs was detected in a study performed in Oporto, Portugal, using zinc sulphate, where $5.1 \%$ of asymptomatic dogs and $7.8 \%$ of gastrointestinal symptomatic dogs admitted to a veterinary hospital tested positive [26]. Nevertheless, the prevalence detected in the present study might be underestimated as several parasites (in particular Toxocara canis) affect mainly puppies, which are not taken to public places or spaces of canine socialisation, because they have not yet been fully vaccinated. This might also be the justification for the low prevalence (1.1\%) of samples positive for Cystoisospora spp., a protozoan that is mostly found in puppies, usually not taken to public places or dog parks. A higher prevalence of Cystoisospora spp. was found in Oporto (13.5\%) in dogs presenting gastrointestinal signs [26]. Other studies performed in Europe reveal higher prevalence, such as central Italy (7.5\%) [29] and Spain (10.2\%) [30].

T. leonina was also found in $1.1 \%$ of the samples, a similar prevalence to the $0.5 \%$ detected in dogs with gastrointestinal signs from Oporto [26].

Sporocysts of Sarcocystis spp. were found in only one sample $(0.3 \%)$, a very low prevalence, possibly explained by the indirect life cycle of this parasite. This parasite was also diagnosed in domestic canids in other researches carried out in Northern Portugal and its prevalence rates were also low [31].

Regarding Trichuris vulpis, heavy infections tend to be geographically localised or to occur mostly in kennels [32], which might explain the lack of positive results for this parasite in the present study.

The high prevalence of detected helminths generally covered by regular deworming products suggests that few dogs are internally dewormed with the recommended schedule (minimum quarterly) [32] despite the frequent contact with other animals. Indeed, the percentage of dewormed dogs in this study is in agreement with Matos et al. [33], who observed that although the majority of Portuguese pet owners give antiparasitic drugs to their pets, most of them do not follow 
the manufacturer's recommendations and veterinary advice, deworming at irregular intervals.

According to Smith et al. [8], infection with enteric parasites is positively associated with off-leash activity, park visitation frequency, and visiting more than one park. In the present study, $82.3 \%$ had off-leash activity, $50.0 \%$ of the dogs visited dog parks daily, and $41.2 \%$ frequented other parks. Additionally, approximately $40 \%$ of the surveyed dogs shared the house with other animals and less than one-third were dewormed according to the recommended regimen. Although $94.1 \%$ of the owners stated that they collect their pet's faeces, 5 to 10 faecal samples were spotted by the authors in each dog park, every sampling date (Ana Ferreira, personal communication). In the study of Matos et al. [33], 63.3\% of the Portuguese dog owners affirmed collecting their dogs' faeces in public areas, $95.6 \%$ whenever this occurs on a city path or pavement and $82.9 \%$ whenever this occurs in city parks. These results match the $94.1 \%$ of the owners who stated that they collect their pet's faeces in the present study. Nevertheless, it could be possible that the percentage found in our study may be overestimated, not reflecting owners' real behaviour, as this is a sensitive matter and data was not collected anonymously. Still, this measure should be encouraged, as it is an extremely important and easy way to reduce environmental contamination to safeguard public and animal health.

Despite the prevalence of the various parasites detected in these dog parks, the present results should be interpreted with caution, as some limitations should be pointed out. Multiple sampling of the same animal(s) cannot be excluded because the source of each faecal sample was not known. In addition, it was not possible to pair survey findings to faecal samples on an individual basis, which hampers the capacity to assess the risk factors of this population. Larvae examination after faecal culture, assessment of Toxocara spp. egg infection ability, and genotyping would have been particularly relevant to determine the hookworm species, the zoonotic potential of Toxocara eggs, and the genotypes of Giardia spp. and Cryptosporidium spp. isolates and, consequently, the potential zoonotic impact of these parasites. The sample size was small regarding the number of samples and geographic distribution, hindering an inference to the whole area of Lisbon. However, one-third of faecal samples with at least one parasite, using the above-mentioned techniques, must be considered a relevant finding for a supposedly well-controlled dog population regarding canine gastrointestinal parasitic diseases, according to the owner's answers. For this reason, further studies are needed involving larger samples and other geographic areas in Portugal, to better understand the potential of dog parks as a transmission source of parasitic diseases for animals and humans.

\section{Conclusions}

In conclusion, soil contamination with the potentially zoonotic hookworm eggs was present in all the parks assessed. In addition, one-third of dog faecal samples contained detectable parasites, including two nematodes with potential zoonotic impact (hookworms and Toxocara spp.) and two potentially zoonotic genera of protozoa (Cryptosporidium spp. and Giardia spp.). Further studies are needed to assess if such risks are present in other dog parks, located in other cities in our country, and all over Europe. Despite being considered for many owners as a destination of excellence for their dogs, these results highlight the potential of dog parks as a source of transmission of several parasitic diseases, especially when considering the high level of human and canine movement in such confined areas. This is particularly likely when appropriate cleaning measures and effective deworming practices are lacking. Additionally, the close physical contact and some behavioural practices reported by several owners not only show a lack of knowledge regarding animal and public health issues but also can pose an increased risk for the transmission of zoonotic diseases. Public awareness and effective preventive measures should be promoted, to minimise the health-risk impact to both animals and humans, under the scope of environmental and public health.

\section{Conflicts of Interest}

The authors declare that there are no conflicts of interest regarding the publication of this paper.

\section{Acknowledgments}

This work was supported by CIISA, Faculdade de Medicina Veterinária, Universidade de Lisboa, Portugal, Reference UID/CVT/00276/2013. The authors would like to thank Dr. Sinclair Owen for providing a revision of the English language.

\section{References}

[1] C. N. L. Macpherson, "Human behaviour and the epidemiology of parasitic zoonoses," International Journal for Parasitology, vol. 35, no. 11-12, pp. 1319-1331, 2005.

[2] D. L. Wells, "The effects of animals on human health and wellbeing," Journal of Social Issues, vol. 65, no. 3, pp. 523-543, 2009.

[3] P. A. M. Overgaauw and F. van Knapen, "Veterinary and public health aspects of Toxocara spp," Veterinary Parasitology, vol. 193, no. 4, pp. 398-403, 2013.

[4] I. D. Robertson and R. C. Thompson, "Enteric parasitic zoonoses of domesticated dogs and cats," Microbes and Infection, vol. 4, no. 8, pp. 867-873, 2002.

[5] H. Sprong, S. M. Cacciò, and J. W. van der Giessen, "Identification of zoonotic genotypes of Giardia duodenalis," PLoS Neglected Tropical Diseases, vol. 3, no. 12, p. e558, 2009.

[6] D. D. Bowman and A. Lucio-Forster, "Cryptosporidiosis and giardiasis in dogs and cats: veterinary and public health importance," Experimental Parasitology, vol. 124, no. 1, pp. 121-127, 2010.

[7] I. D. Robertson, P. J. Irwin, A. J. Lymbery, and R. C. A. Thompson, "The role of companion animals in the emergence of parasitic zoonoses," International Journal for Parasitology, vol. 30, no. 12-13, pp. 1369-1377, 2000.

[8] A. F. Smith, C. A. D. Semeniuk, S. J. Kutz, and A. Massolo, "Dogwalking behaviours affect gastrointestinal parasitism in parkattending dogs," Parasites and Vectors, vol. 7, no. 1, article no. 429, 2014. 
[9] B. Brochier, H. De Blander, R. Hanosset, D. Berkvens, B. Losson, and C. Saegerman, "Echinococcus multilocularis and Toxocara canis in urban red foxes (Vulpes vulpes) in Brussels, Belgium," Preventive Veterinary Medicine, vol. 80, no. 1, pp. 65-73, 2007.

[10] A. Wang, R. Ruch-Gallie, V. Scorza, P. Lin, and M. R. Lappin, "Prevalence of Giardia and Cryptosporidium species in dog park attending dogs compared to non-dog park attending dogs in one region of Colorado," Veterinary Parasitology, vol. 184, no. 2-4, pp. 335-340, 2012.

[11] M. W. Dryden, P. A. Payne, R. Ridley, and V. Smith, "Comparison of common fecal flotation techniques for the recovery of parasite eggs and oocysts," Veterinary Therapeutics, vol. 6, no. 1, pp. 15-28, 2005.

[12] W. J. Foreyt, Veterinary Parasitology Reference Manual, WileyBlackwell, Hoboken, NJ, USA, 5th edition, 2001.

[13] A. M. Zajac and G. A. Conboy, Veterinary Clinical Parasitology, Wiley-Blackwell, Hoboken, NJ, USA, 8th edition, 2012.

[14] D. D. Bowman, Georgis' Parasitology for Veterinarians, Elsevier Saunders, Louis, Mo, 10th edition, 2014.

[15] J. R. Barta, M. D. Schrenzel, R. Carreno, and B. A. Rideout, "The genus Atoxoplasma (Garnham 1950) as a junior objective synonym of the Genus Isospora (Schneider 1881) species infecting birds and resurrection of Cystoisospora (Frenkel 1977) as the correct genus for Isospora species infecting Mammals," Journal of Parasitology, vol. 91, no. 3, pp. 726-727, 2005.

[16] D. P. Casemore, M. Armstrong, and R. L. Sands, "Laboratory diagnosis of cryptosporidiosis," Journal of Clinical Pathology, vol. 38, no. 12, pp. 1337-1341, 1985.

[17] H. Mizgajska-Wiktor, "Recommended method for recovery of Toxocara and other geohelminth eggs from soil," Wiadomości parazytologiczne, vol. 51, pp. 21-22, 2005.

[18] V. A. Santarém, L. P. Magoti, and T. D. Sichieri, "Influence of variables on centrifuge-flotation technique for recovery of Toxocara canis eggs from soil," Revista do Instituto de Medicina Tropical de Sao Paulo, vol. 51, no. 3, pp. 163-167, 2009.

[19] R. C. Anderson, Nematode Parasites of Vertebrates: Their Development and Transmission, CABI Publishing, Wallingford, Oxon UK, 2nd edition, 2000.

[20] T. L. Mateus, A. Castro, J. N. Ribeiro, and M. Vieira-Pinto, "Multiple zoonotic parasites identified in dog feces collected in Ponte de Lima, Portugal-a potential threat to human health," International Journal of Environmental Research and Public Health, vol. 11, no. 9, pp. 9050-9067, 2014.

[21] F. S. Ferreira, P. Pereira-Baltasar, R. Parreira et al., "Intestinal parasites in dogs and cats from the district of Évora, Portugal," Veterinary Parasitology, vol. 179, no. 1-3, pp. 242-245, 2011.

[22] P. Prociv and J. Croese, "Human enteric infection with Ancylostoma caninum: hookworms reappraised in the light of a 'new' zoonosis," Acta Tropica, vol. 62, no. 1, pp. 23-44, 1996.

[23] E. Claerebout, S. Casaert, A.-C. Dalemans et al., "Giardia and other intestinal parasites in different dog populations in Northern Belgium," Veterinary Parasitology, vol. 161, no. 1-2, pp. 41-46, 2009.

[24] M. Osman, J. Bories, D. El Safadi et al., "Prevalence and genetic diversity of the intestinal parasites Blastocystis sp. and Cryptosporidium spp. in household dogs in France and evaluation of zoonotic transmission risk," Veterinary Parasitology, vol. 214, no. 1-2, pp. 167-170, 2015.

[25] P. J. Irwin, "Companion animal parasitology: a clinical perspective," International Journal for Parasitology, vol. 32, no. 5, pp. 581-593, 2002.
[26] D. Neves, L. Lobo, P. B. Simões, and L. Cardoso, "Frequency of intestinal parasites in pet dogs from an urban area (Greater Oporto, northern Portugal)," Veterinary Parasitology, vol. 200, no. 3-4, pp. 295-298, 2014.

[27] M. L. Lobo, L. Xiao, F. Antunes, and O. Matos, "Occurrence of Cryptosporidium and Giardia genotypes and subtypes in raw and treated water in Portugal," Letters in Applied Microbiology, vol. 48, no. 6, pp. 732-737, 2009.

[28] D. Otero, R. Nijsse, L. Gomes et al., "Prevalência de ovos de Toxocara spp. no solo de parques públicos da área da grande Lisboa, Portugal-resultados preliminares," Acta Parasitológica Portuguesa, vol. 20, no. 1/2, pp. 47-50, 2014.

[29] F. Riggio, R. Mannella, G. Ariti, and S. Perrucci, "Intestinal and lung parasites in owned dogs and cats from central Italy," Veterinary Parasitology, vol. 193, no. 1-3, pp. 78-84, 2013.

[30] F. J. Martínez-Moreno, S. Hernández, E. López-Cobos, C. Becerra, I. Acosta, and A. Martínez-Moreno, "Estimation of canine intestinal parasites in Córdoba (Spain) and their risk to public health," Veterinary Parasitology, vol. 143, no. 1, pp. 7-13, 2007.

[31] M. S. Silva, Survey of gastrointestinal, lung, cutaneous and muscle parasites from wild and domestic canids in the North of Portugal (Rastreio de parasitas gastrintestinais, pulmonares, cutâneos e musculares em canídeos domésticos e silvestres no Norte de Portugal) [M.S. thesis], Faculty of Veterinary Medicine, Technical University of Lisbon, Lisbon, Portugal, 2010.

[32] T. Schnieder, "Worm control (helminth) in cats and dogs: German adaptation of the ESCCAP recommendation, December 2007 - European Scientific Counsel Companion Animal Parasites (ESCCAP)," Journal fur Verbraucherschutz und Lebensmittelsicherheit, vol. 3, no. 2, pp. 201-215, 2008.

[33] M. Matos, A. M. Alho, S. P. Owen, T. Nunes, and L. Madeira de Carvalho, "Parasite control practices and public perception of parasitic diseases: A survey of dog and cat owners," Preventive Veterinary Medicine, vol. 122, no. 1-2, pp. 174-180, 2015. 


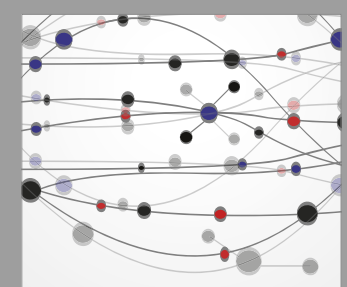

The Scientific World Journal
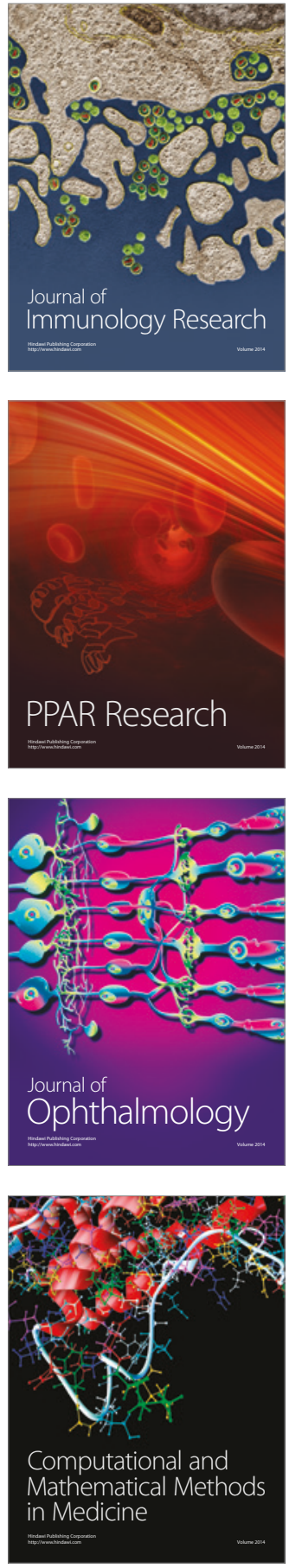

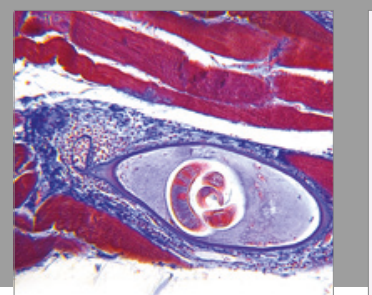

Gastroenterology Research and Practice
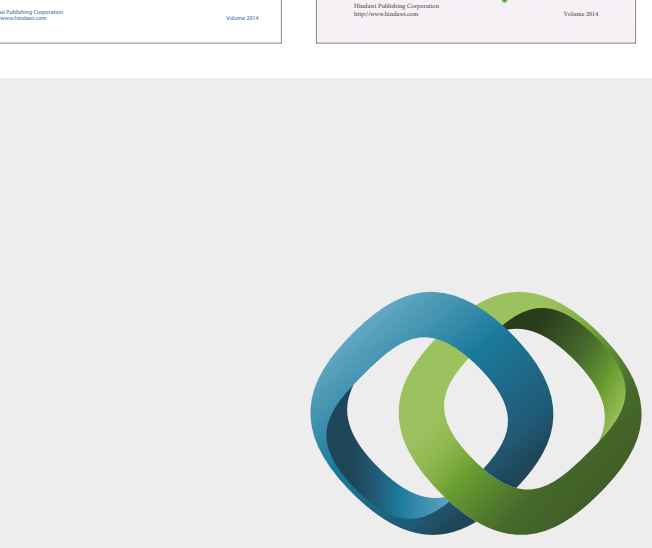

\section{Hindawi}

Submit your manuscripts at

https://www.hindawi.com
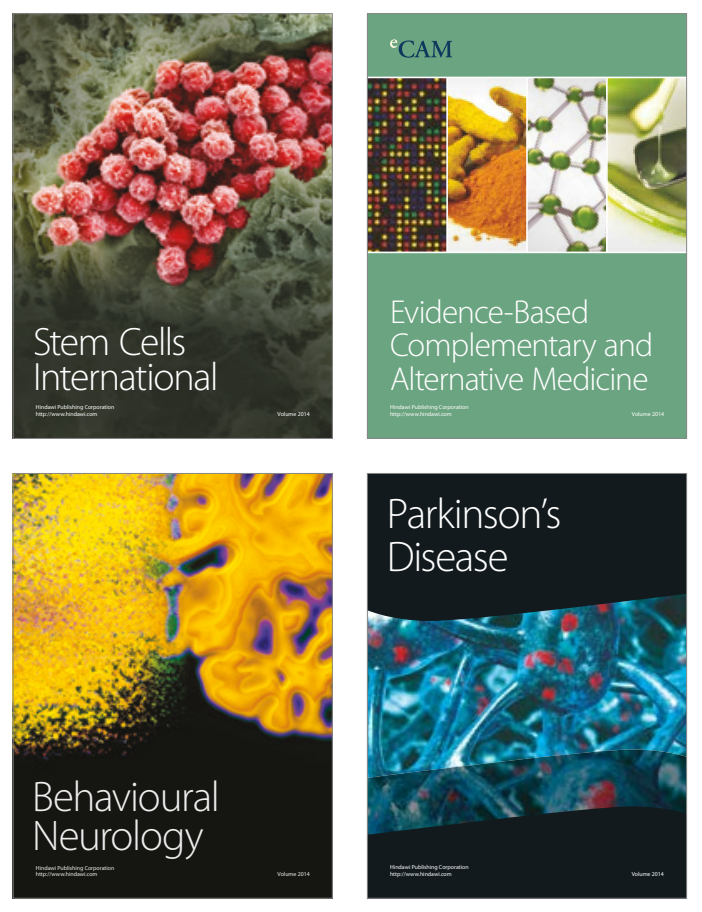
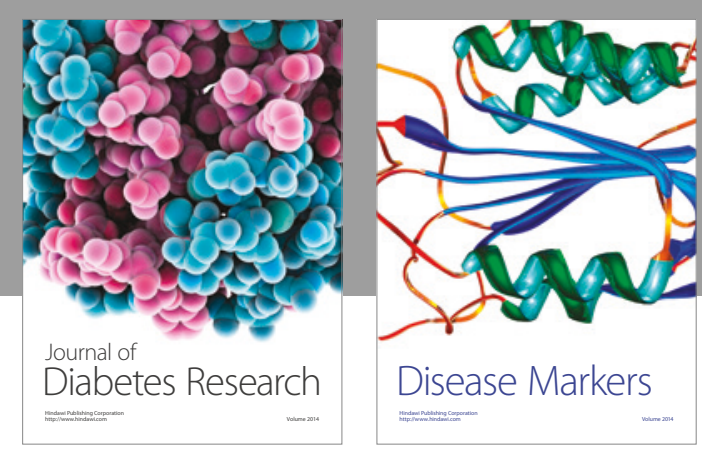

Disease Markers
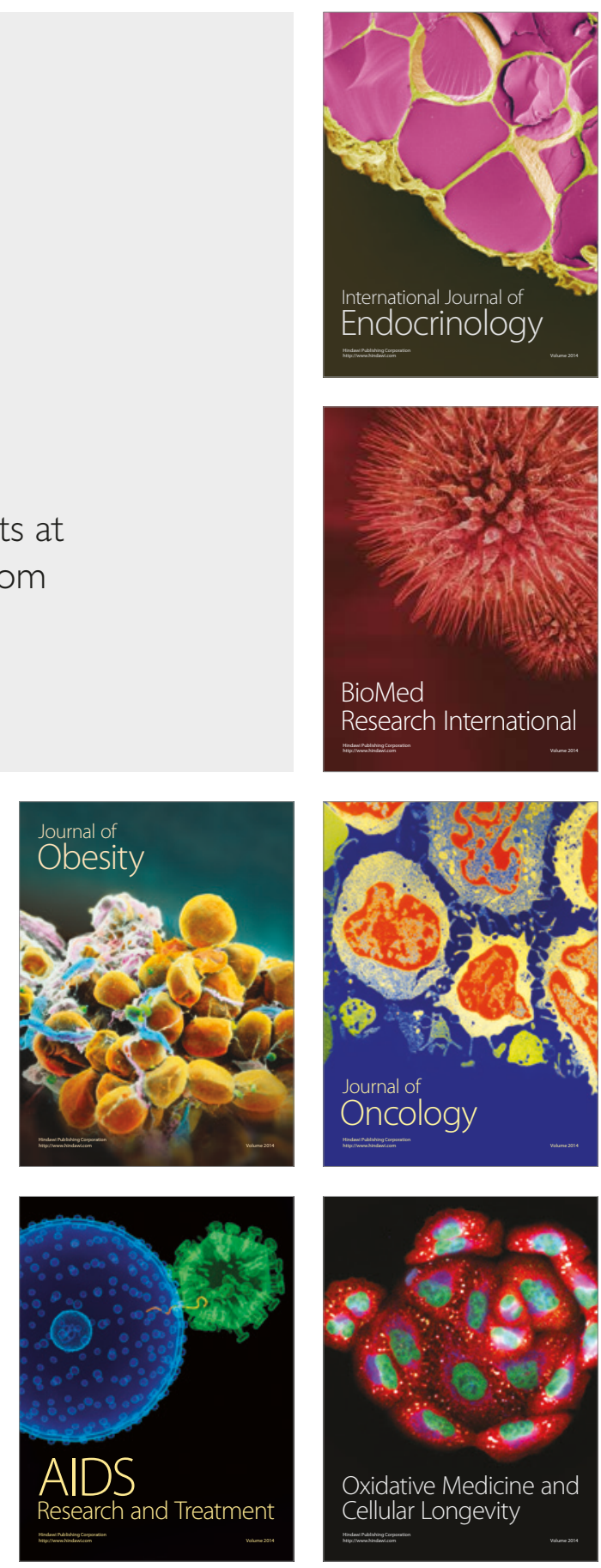